\title{
Airport Emissions of Particulate Matter
}

\author{
Bc. Jaroslav Sterba \\ Faculty of Transportation Sciences \\ Czech Technical University \\ Czech Republic, Prague
}

\author{
Ing. Bc. Jakub Hospodka Ph.D. \\ Faculty of Transportation Sciences \\ Czech Technical University \\ Czech Republic, Prague
}

\begin{abstract}
This article presents an overview and results of research of Airport Emissions of Particulate Matter (AEoPM). The AEoPM thesis creates an environment for summarizing local airport particulate matter emissions, for evaluating their contribution to overall local air pollution and for comparing the relative contributions to overall particulate matter emissions from each individual source of emission. The study researches the situation at Hradec Králové regional airport and then applies this gathered data to the airport's surrounding area. Next it poses the question: Is it appropriate to restrict Hradec Králové Airport's operations when emission limits are breached? The answer is then found and presented in this article. Last but not least, the study deals with other local industry sources of particulate matter emissions in the monitored area and also compares the typical flight activity to the road activity one commonly used in the area.
\end{abstract}

\section{Particulate matter; emissions; airport; aircraft; air pollution}

\section{INTRODUCTION}

This paper contributes to the current effort of mapping emissions having an impact on the environment. The theme is as apparent from the current debate and latest researches in this field. Particulate matter emissions have indisputable impacts, e.g. on human health, agricultural harvests, land contamination, corrosion of constructional materials and so on.

The proceeding information concerns the methodical approach taken in relation to the airport particulate matter emissions contribution evaluation. Then the calculations, overall concept and its application to the Hradec Králové airport are presented. Additionally, answers to the following questions are included:

1) How significant a contributor is Hradec Králové airport to local air pollution?

2) Is it worth restricting airport operations when local air quality limits are breached?

3) How the individual types of flight operation contribute to the overall flight operation particulate matter emissions and to the overall airport emissions?
4) Is it meaningful to compare the emissions indices of the most frequently observed road vehicle with the most frequent aircraft of the same passenger capacity used in the monitored area?

5) What is the result of comparing the regional Hradec Králové Airport with the biggest Czech international Václav Havel airport, Prague?

The answers to these and other interesting questions concerning the particulate matter emissions produced in the relation to airport operations, can be found in the text below.

\section{CALCULATION AND COMPARISON METHODOLOGY}

This work is based on the calculation of the total particulate matter emissions levels in a designated area (the Air Traffic Zone of Hradec Králové as explained below) over the monitored period i.e. from the January to the April 2011 (the period was chosen due to the movements data availability).

The total amount of these emissions is computed as the sum of the individual contributions i.e. the emission sources.

The calculations of particulate matter emissions produced by the individual types of flight operations are different one from the other. They differ in their accuracy, in the types of particulate matter emissions recorded and of course in the overall emission levels. This work then search for communal characteristics of emissions produced for the final comparisons.

The project then evaluates the total amount of static local industry polluters in the designated area by summing the individual annual particulate matter emission contributions. This calculation brings interesting answers to the airport operation restriction question.

The study then compares the most common 4 passenger airplane - Cessna 172 with typical road passenger vehicle (as defined below) by transferring the emission indices of Cessna 172 from the [gram of the emissions produced on the burnt kilogram of fuel] to the [gram of the emissions produced on 
the distance flown] for comparison to the road vehicles indices with the distance travelled.

The calculations at Václav Havel Airport Prague are based on data relating to the emission sources at this airport from a study about the impacts of the potential construction of a parallel runway [1]. The total emission reading is then recalculated for an area of comparable size for comparison with the Hradec Králové Airport.

The reasons why the Hradec Králové Airport was chosen for the study are as follows:

- The movements data availability

- The author's experience with local airport operations

- The variability of the types of operation (flight training, air taxi, rescue, sight-seeing flights...)

- The structure of examined area - the radius of arrival and departure area is fixed (ATZ) thereby appropriate for total amount calculations.

- The monitored area contains a big portion of the surrounding city - Hradec Králové, therefore the results could be interesting for local inhabitants.

\section{AIRCRAFT PM EMISSIONS IN THE VICINITY OF THE HRADEC KRÁLOVÉ AIRPORT}

We could determine the structure of the operation from the movements data for the year 2011. Because of the large amount of data and it all being in handwritten form, only the portion of the year - January to April 2011 was analysed (it is 7,385 from the 28,703 movements).

The analysis shows that slightly more than $50 \%$ of all movements are done by Cessna 172 from about 56 types of the aircraft operated in that period in HK airport and all piston engine aircraft together are responsible for about $88 \%$ of all movements. Jet aircraft accounts for less than $1 \%$ of all movements, turboprops about $1 \%$ and helicopters about $11 \%$.

We are able to estimate the particulate matter emissions from the emissions characteristic investigated by different organizations. The FOCA created emission inventories of helicopter and piston engine activity, the ICAO made an EEDB inventory of jet engines and the FOI made a turboprop emission inventory (unfortunately this is the only one without PM emission indices so another way to estimate these indices had to be found as described below). We were able to calculate following particulate matter emissions for various types of aircraft:

- non-volatile PM emissions for JET, piston, turboprop and helicopter engines

- $\quad$ organic and sulphur volatile PM only for JET engines
The calculations based on typical times of LTO cycle phases in $\mathrm{HK}$ airport, characteristics from databases and movements data shows that in the monitored area and period the individual types of operation are responsible for the following:
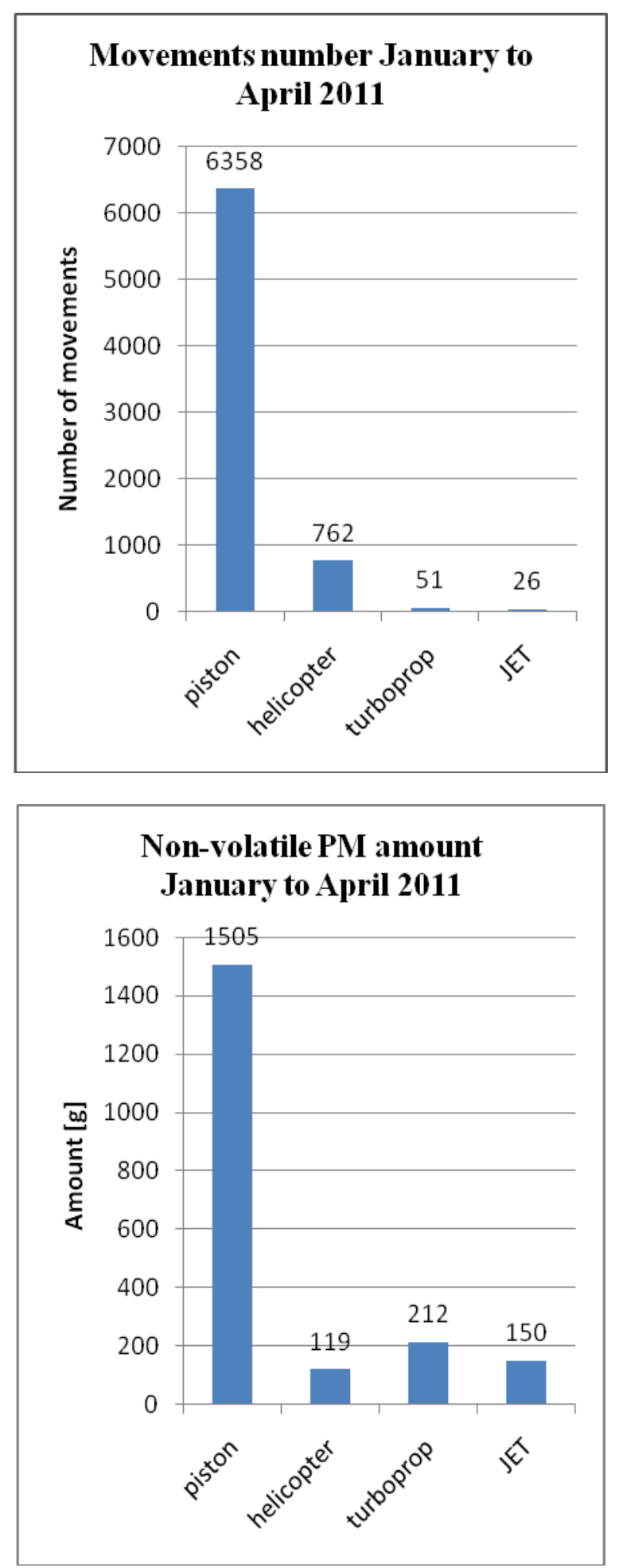
As we can see from above information, the JET and turboprops have a significant contribution to overall PM emissions in spite of the low number of movements in monitored period. The overall amount of aircraft/helicopter non-volatile PM emissions is about 2 kilograms of PM from January to April 2011. The amount of volatile emissions is not easy to estimate because of the lack of knowledge relating to piston and turboprop characteristics but in JET engine operation at $\mathrm{HK}$ airport the overall PM emissions are about twice the amount of non-volatile PM emissions.

TABLE I. TYPICAL AIRCRAFT PM EMISSIONS INDICES [G/KG]

\begin{tabular}{|c|c|c|c|c|}
\hline Typical aircraft & Take-off & Climb & Approach & Taxi \\
\hline C525(JET) & 0,01 & 0,01 & 4,43 & 50,5 \\
\hline C172(piston) & 0,1 & 0,07 & 0,04 & 0,05 \\
\hline R22(helicopter) & 0,05 & 0,1 & 0,04 & 0,05 \\
\hline PA42(turboprop) & 0,15 & 0,15 & 0,15 & 0,15 \\
\hline
\end{tabular}

\section{OVERALL AIRPORT PM EMISSIONS}

The HK airport does not have significant ground sources of emissions because it is only a regional airport with most of its flight activity executed by small piston engine aircraft so the biggest question other than concerning flight activity is the road traffic contribution to overall emissions relative to the airport operation.

The only significant road traffic related to HK airport is the employees and clients travelling to the airport by cars in monitored area. The three most often utilized access ways were identified and emissions of these routes to the airport and back from the edge of the area were calculated with use of MEFA v6.0 modelling software and average length of the access ways. Typical 4 passenger cars were used for these calculations. The results are interesting:

TABLE II. TYPICAL ROAD 4 PASSENGERS VEHICLE PM EMISSIONS INDICES $[\mathrm{G} / \mathrm{KM}]$

\begin{tabular}{|c|c|c|c|c|c|}
\hline $\mathbf{9 0} \mathbf{~ k m} / \mathbf{h}$ & Conv. & EUR 1 & EUR 2 & EUR 3 & EUR 4 \\
\hline $\begin{array}{c}\text { EIpm } \\
\text { diesel }\end{array}$ & 0,329 & 0,1551 & 0,0637 & 0,0331 & 0,0234 \\
\hline $\begin{array}{c}\text { EIpm } \\
\text { petrol }\end{array}$ & 0,0041 & 0,0014 & 0,0014 & 0,0014 & 0,0014 \\
\hline $\mathbf{5 0} \mathbf{~ k m / h}$ & Conv. & EUR 1 & EUR 2 & EUR 3 & EUR 4 \\
\hline $\begin{array}{c}\text { EIpm } \\
\text { diesel }\end{array}$ & 0.3218 & 0.1941 & 0.0741 & 0.0412 & 0.0215 \\
\hline $\begin{array}{c}\text { EIpm } \\
\text { petrol }\end{array}$ & 0.0016 & 0.0005 & 0.0005 & 0.0005 & 0.0005 \\
\hline
\end{tabular}

- There are enormous differences between the most polluting conventional diesel cars and the most clean gasoline EURO $4 *$ cars between $0.0086 \mathrm{~g}$ to $5.5160 \mathrm{~g}$ produced on the average access way to the airport.

\section{* The highest category in the MEFA v6.0 software is EUR4}

- When using an average car determined from the RSD CR study of the road traffic structure [2] the estimation of one return journey to and from $\mathrm{HK}$ airport produces $0.349 \mathrm{~g}$

- By transforming the Cessna 172 average emission characteristic during operation in monitored are we get $0.0119 \mathrm{~g} / \mathrm{km}$ which is close to the dirtier gasoline cars but cleaner than some diesel cars.[3]

So when considering the probable average scenario of 0.349 grams of PM produced by one return journey to and from HK airport by a client or an employee we see that overall aircraft/helicopter PM production $1986 \mathrm{~g}$ is equal to about 5690 return to the airport and back by car. The monitored period is 120 days which means about 47 return journeys per day. In our scenario, we do not know the average number of clients or employees but our investigation showed that road traffic related to the $\mathrm{HK}$ airport is of great importance and may even be responsible for more PM emissions than air operations in some scenarios.

\section{COMPARISON TO LOCAL INDUSTRY SOURCES}

For the purposes of evaluating local industry PM emission sources, the data about these sources was obtained from the Czech Hydrometeorological Institute. In the ArcGis software the sources in the radius of the ATZ HK were picked up and consequently quantified and the results are very useful for the purposes of determining the importance (or unimportance) of Airport operations relative to the PM emissions contribution to local pollution.

The total amount of local industry PM emissions was 11.069 tons in the radius of the ATZ in 2011. One factory only is responsible for more than 7 tons, 7 factories produced amounts of about hundred kilograms, 10 factories in the tens of $\mathrm{kg}$ and 29 factories only a few kilograms per year.

The large size diversity of the PM emission production shows that the individual sources are incomparable to each other but more importantly, compared to the airport operation - the HK airport contribution to local air quality is minute. That is to answer the question about restricting HK airport operations when the limits are breached.

\section{HRADEC KRÁlOVÉ AiRPORT VS. VÁClAV HAVEL AIRPORT PRAGUE}

A comparison of HK regional airport to the Czech Republic's biggest international airport was made. The data about LKPR (the ICAO designator for Václav Havel Airport Prague) PM emissions sources was extracted from a study about the impact of the construction of a future parallel runway [1]. This data was summarized for the individual airport sources, such as 
ground vehicle movements, road traffic related to the airport, aircraft and static PM emission sources.

The radius of the researched area was determined from the maps in the parallel runway study and the amount of PM emissions were then recalculated for an area equal to the ATZ LKHK for the purposes of getting a better overall picture for comparing these two airports.

The PM emissions amount produced in LKPR during the period January to April 2011, in an equal area was then estimated at about $202 \mathrm{~kg}$. That means about one hundred times the HK airport PM emissions production.

When categorizing the local industry sources to categories corresponding with the sources in ATZ LKHK radius to: large (with tons of PM emissions annually), big (hundreds of $\mathrm{kg}$ ), medium (tens of $\mathrm{kg}$ ), small (units of $\mathrm{kg}$ ) then the LKPR airport corresponds to the big PM emissions sources and has a significant influence on the surrounding environment. The LKHK airport would be in the category small and thereby its significance when comparing to local industry sources is very small.

\section{CONCLUSIONS}

The results of research utilized various approaches to evaluating the airport PM emissions contribution to the local air quality. This research also answers the questions mentioned in the introduction:
1) LKHK has a minute contribution to the local air quality when comparing to other local sources and the aircraft operation may have lesser or equal impact to the air quality than the road traffic related to the airport's operations.

2) Thereby restrictions of airport operations are useless.

3) The contributions of individual types of operation are mentioned in the chapter III.

4) The emissions characteristics of the average air transport facility in the researched area ATZ LKHK is comparable to the average road vehicle used in the relation to the airport operation.

5) Comparing the LKPR and LKHK airports shows that LKPR has a significant influence on the local air quality and the LKHK has only a minor contribution.

\section{ACKNOWLEDGMENT}

J.S. thanks to Mgr. Lenka Monk for language consultation.

\section{REFERENCES}

[1] T. Bajer, M. Sara and J. Bajerova, The Documentation of the Parallel Runway Environmental Impacts at the Prague Airport, Prague, 2010

[2] V. Pisa, The Current Dynamic Structure of the Vehicle Fleet in the Czech Road Net and its Emission Parameters, Road and Motorway Directorate of the Czech Republic, Prague, 2010, pp.70

[3] J. Sterba, Airport Emissions of Particulate Matter, Czech Technical University, Prague, p.3.10. 